\title{
Erratum
}

\section{Erratum to "Whole-Body Vibration Exercise for Knee Osteoarthritis: A Systematic Review and Meta-Analysis"}

\author{
Xin Li, ${ }^{1}$ Xue-Qiang Wang, ${ }^{2,3}$ Bing-Lin Chen, ${ }^{2}$ Ling-Yan Huang, ${ }^{1}$ and Yu Liu ${ }^{1}$ \\ ${ }^{1}$ Key Laboratory of Exercise and Health Sciences of the Ministry of Education, Shanghai University of Sport, Heng Ren Road, \\ No. 200, Yang Pu District, Shanghai 200438, China \\ ${ }^{2}$ School of Kinesiology, Shanghai University of Sport, Qing Yuan Huan Road, No. 650, Yang Pu District, Shanghai 200438, China \\ ${ }^{3}$ Department of Sport Rehabilitation, Shanghai University of Sport, Chang Hai Road, No. 399, Yang Pu District, \\ Shanghai 200438, China \\ Correspondence should be addressed to Yu Liu; yuliu@sus.edu.cn \\ Received 5 October 2015; Accepted 8 October 2015 \\ Copyright (C) 2015 Xin Li et al. This is an open access article distributed under the Creative Commons Attribution License, which \\ permits unrestricted use, distribution, and reproduction in any medium, provided the original work is properly cited.
}

In our paper entitled "Whole-Body Vibration Exercise for Knee Osteoarthritis: A Systematic Review and Meta-Analysis" [1], there was an error in the journal name and the authors' names of reference number [27] mentioned in the references list. We have now provided new corrected reference number [27]:

[27] P. R. da Costa, D. da Cunha Sá-Caputo, A. Arnóbio et al., "Whole-body vibration and benefits for people with osteoarthritis: a system review," International Journal of Medicine and Medical Sciences, vol. 6, no. 9, pp. 201-210, 2014.

These corrections do not change any conclusion or findings of the paper.

\section{References}

[1] X. Li, X.-Q. Wang, B.-L. Chen, L.-Y. Huang, and Y. Liu, "Wholebody vibration exercise for knee osteoarthritis: a systematic review and meta-analysis," Evidence-Based Complementary and Alternative Medicine, vol. 2015, Article ID 758147, 11 pages, 2015. 


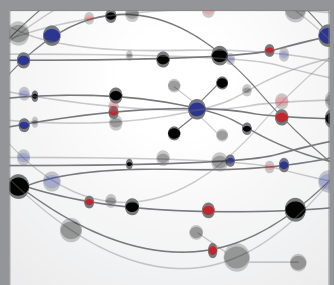

The Scientific World Journal
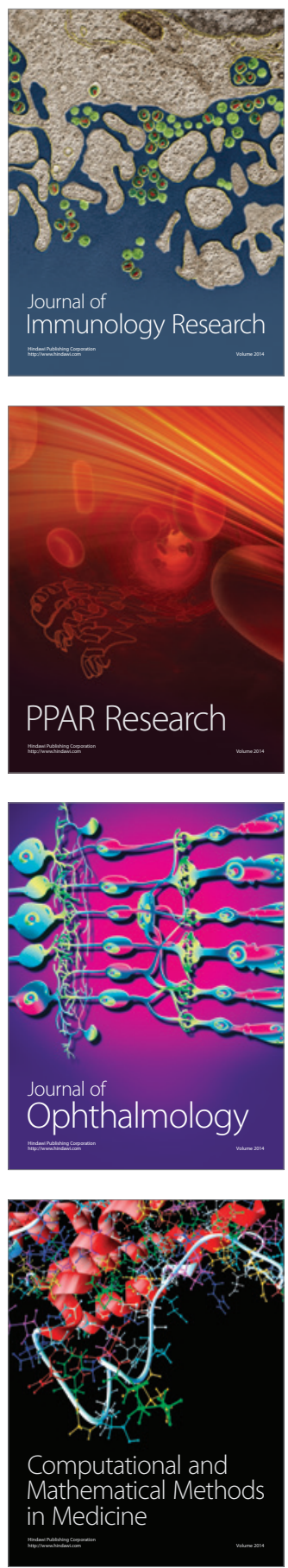

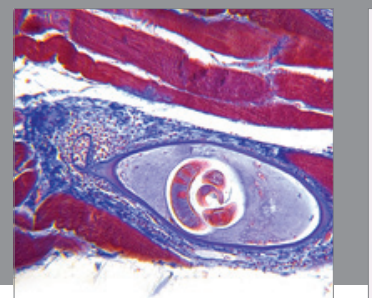

Gastroenterology

Research and Practice
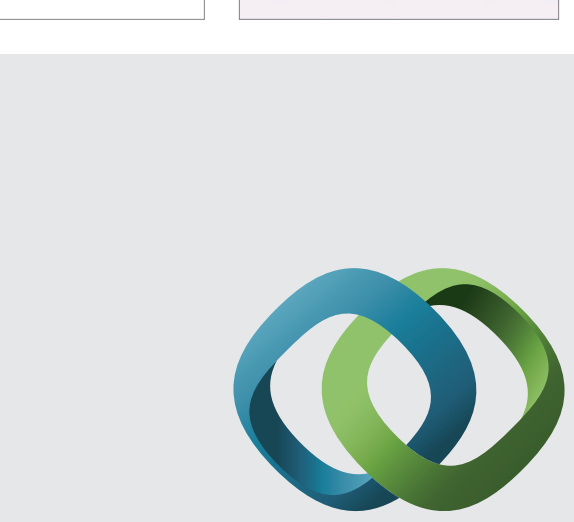

\section{Hindawi}

Submit your manuscripts at

http://www.hindawi.com
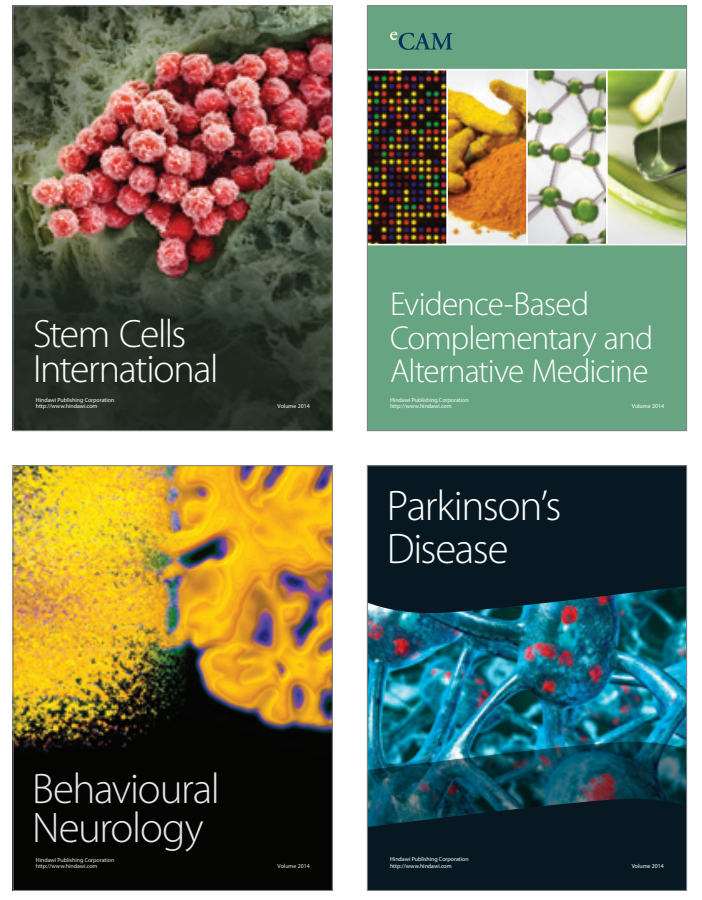
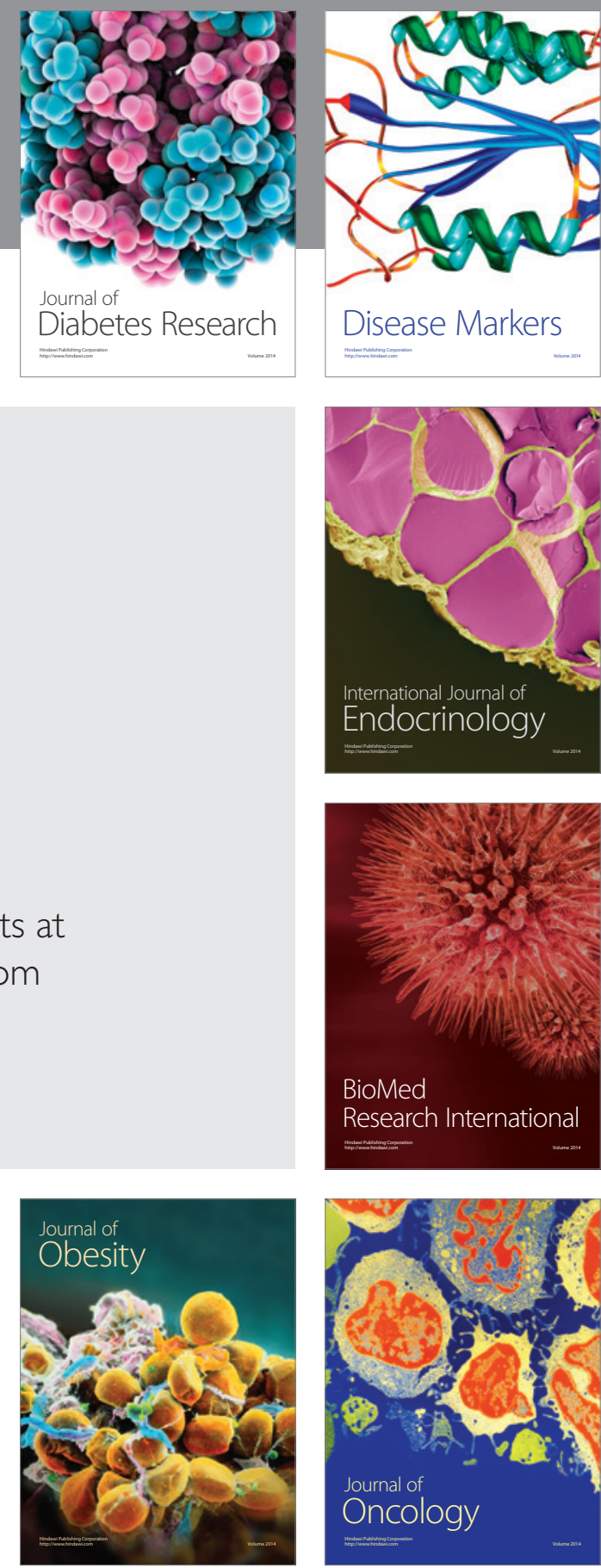

Disease Markers
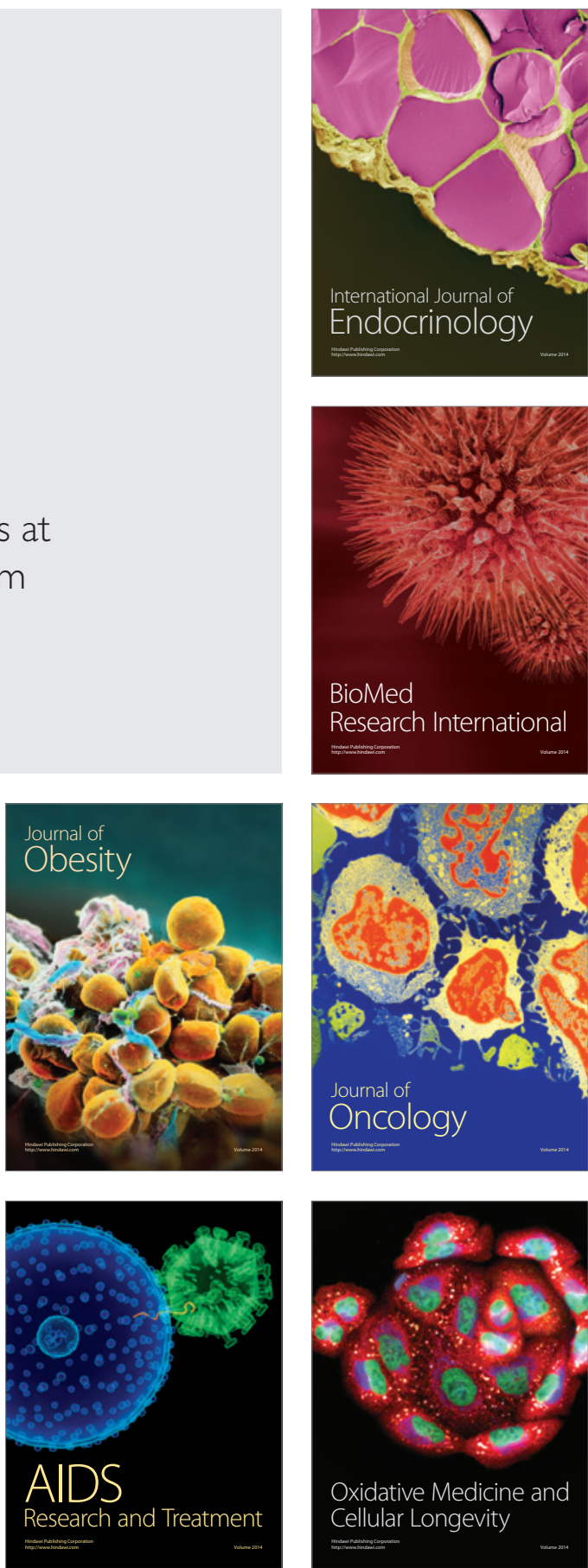